\title{
Activity of tocopherol oxidase in Phaseolus coccineus seedlings
}

\author{
Renata Szymańska $\cdot$ Jerzy Kruk
}

Received: 15 April 2013/Revised: 17 April 2013/Accepted: 19 April 2013/Published online: 27 April 2013

(C) The Author(s) 2013. This article is published with open access at Springerlink.com

\begin{abstract}
In the present study, we have demonstrated that membrane-free extracts of etiolated shoots of Phaseolus coccineus seedlings show tocopherol oxidase activity. For this reaction, presence of membrane lipids, such as lecithin and mixture of plant lipids was required. The rate of the reaction was the highest for $\alpha$-tocopherol and decreased in the order $\alpha \gg \beta>\gamma>\delta$ tocopherols. In the case of $\alpha$-tocopherol, the main oxidation product was $\alpha$-tocopherolquinone, while for the other tocopherol homologues the dominant products were other derivatives. When the enzyme activity was measured in leaves, hypocotyls and roots of etiolated seedlings of $P$. coccineus, the oxidase activity was the highest in extracts of leaves and decreased towards the roots where no activity was detected. The effect of hydrogen peroxide and of different inhibitors on the reaction suggest that tocopherol oxidase does not belong to peroxidases or flavin oxidases but rather to multicopper oxidases, such as polyphenol oxidases or laccases. On the other hand, catechol, the well-known substrate of polyphenol oxidases and laccases, was not oxidized by the enzyme, indicating a high substrate specificity of the tocopherol oxidase.
\end{abstract}

Keywords Phaseolus coccineus - Oxidase - Tocopherol · Tocopherolquinone

Communicated by L. A. Kleczkowski.

R. Szymańska · J. Kruk ( $\bowtie)$

Department of Plant Biochemistry and Physiology, Faculty

of Biochemistry, Biophysics and Biotechnology, Jagiellonian

University, Gronostajowa 7, 30-387 Kraków, Poland

e-mail: jerzy.kruk@uj.edu.pl

\author{
Abbreviations \\ DGDG Digalactosyldiacyl glycerol \\ MGDG Monogalactosyldiacyl glycerol \\ PG Phosphatidyl glycerol \\ SQDG Sulphoquinovosyldiacyl glycerol \\ Toc Tocopherol \\ TQ Tocopherolquinone
}

\section{Introduction}

In contrast to biosynthesis of tocopherols, which is intensively investigated and well known (Mène-Saffrané and DellaPenna 2010; Lushchak and Semchuk 2012), catabolism of these compounds in plants is poorly characterized. It is generally believed that tocopherols degradation in plant tissues proceeds only non-enzymatically due to their oxidation by reactive oxygen species, which is the result of antioxidant function of these compounds (Gruszka et al. 2008; Munne-Bosch and Alegre 2002). During oxidation of $\alpha$-tocopherol, various oxidation products are formed, but the most stable and specific is $\alpha$-tocopherolquinone ( $\alpha$-TQ) (Gruszka et al. 2008). However, there exist few data indicating a possibility of enzymatic oxidation of tocopherols. For example, tocopherols were found to be oxidized by lipoxygenase in vitro (Hakansson and Jagerstad 1990). Moreover, in early 1960s, it was demonstrated that cellfree extracts from etiolated shoots of Pisum sativum, seeds of Pisum sativum and Phaseolus vulgaris or leaves of Xanthium struminarium show activity in tocopherol degradation (Barlow and Gaunt 1968; Gaunt and Stowe 1967; Murillo et al. 1978; Gaunt and Plumpton 1978). The enzyme responsible for this reaction was named tocopherol oxidase and catalyzes oxidation of $\alpha$-tocopherol by 
molecular oxygen. Activity of this enzyme was found in many plant organs like roots, stems, leaves, flowers and fruits (Murillo et al. 1978). It was postulated that the enzyme is responsible for vitamin E loss in food (Murillo et al. 1978). Besides molecular oxygen, the oxidase was shown to require phospholipids for its activity (Gaunt and Barlow 1971). The enzyme was not only specific in $\alpha$-tocopherol oxidation but also oxidized other tocopherol forms, however, with a lower rate (Murillo et al. 1978). Tocopherol oxidase was also found to be controlled in vitro by phytohormones (Gaunt et al. 1980) and showed photoperiodic control both in vivo and in vitro (Gaunt and Plumpton 1980).

The recent analysis of tocopherols composition of etiolated runner bean seedlings and light-grown plants (Szymańska and Kruk 2008) indicated specific degradation of $\gamma$-tocopherol during development of young tissues in $P$. coccineus. Therefore, in the present study we decided to re-investigate the issue of the occurrence of tocopherol oxidase activity in etiolated shoots of runner bean and to further characterize the enzyme.

\section{Materials and methods}

\section{Plant material and extract preparation}

The extracts were prepared from etiolated shoots of $P$. coccineus cv. Piękny Jaś grown for 7-10 days at $20 \pm 2{ }^{\circ} \mathrm{C}$. The shoots were homogenized $15 \mathrm{~s}$ with Philips blender in $50 \mathrm{mM}$ citrate-phosphate buffer $\mathrm{pH} 5.5$ using $0.5 \mathrm{ml}$ of the buffer for every $1 \mathrm{~g}$ of the fresh weight (Gaunt and Barlow 1971). Usually, 40-60 g of the tissue was used. The homogenate was filtered through six cloth layers and centrifuged at $1,000 \mathrm{~g}$ for $10 \mathrm{~min}$ at $4{ }^{\circ} \mathrm{C}$. The pellet was discarded and the supernatant was centrifuged on Beckman J2-MC centrifuge at $30,000 \mathrm{~g}$ for $80 \mathrm{~min}$ at $4{ }^{\circ} \mathrm{C}$. The obtained supernatant was used for the experiments. The protein concentration was $1.4 \pm 0.2 \mathrm{mg} / \mathrm{ml}$ in the supernatant. In some experiments, where indicated, only leaves, hypocotyls or roots were used for the preparation of the homogenate.

Liposome preparation and determination of tocopherol oxidase activity

Liposomes were formed by mixing of appropriate amounts of tocopherol and membrane lipids in ethanol and slow injection of the mixture into the homogenate. The membrane lipids used were egg yolk lecithin (Sigma-Aldrich Germany, type V-E) the mixture of plant lipids: MGDG, DGDG, PG, SQDG (50:25:12.5:12.5, mol/mol) (Lipid Products, England). The final volume of the reaction mixture was $2 \mathrm{ml}$, the injection volume was $100 \mu \mathrm{l}$, the final membrane lipid concentration- $1 \mathrm{mM}$ and that of tocopherol-100 $\mu \mathrm{M}$. The reaction was performed at $20 \pm 2{ }^{\circ} \mathrm{C}$, unless otherwise stated, under magnetic stirring.

The progress of the reaction was followed by HPLC. The samples for HPLC analysis were taken at 0, 30, 60 and $90 \mathrm{~min}$ of the reaction. The tocopherols and their oxidation products were extracted using $300 \mu$ of ethyl acetate for $100 \mu \mathrm{l}$ of the reaction mixture. The extracting mixture was placed in an Eppendorf tube, vortexed for 1 min followed by centrifugation $(3 \mathrm{~min} \times 10,000 \mathrm{~g}$, Eppendorf Mini Spin Plus) and drying under stream of nitrogen, dissolved in the HPLC solvent (acetonitrile/methanol/water; 72/8/1, v/v) and analyzed by HPLC as described in Szymańska and Kruk (2008).

Tocopherol homologues were from Calbiochem, while tocopherolquinones and their reduced forms were obtained as described in Kruk (1988a, b).

\section{Results}

The cell-free homogenate showed tocopherol oxidase activity when $\alpha$-tocopherol was incorporated both into lecithin and plant lipid liposomes, but no activity was found in the absence of liposomes (Fig. 1a). It was also found that $\alpha$-tocopherol is not oxidized in the absence of the homogenate in both types of liposomes. In the case of lecithin liposomes, the activity was considerably higher than for plant lipid liposomes. Investigation on substrate specificity of the oxidase showed that the enzyme shows the highest activity against $\alpha$-tocopherol, followed by $\beta$-tocopherol, $\gamma$ - and $\delta$-tocopherols (Fig. 1b). The activity of the latter tocopherol homologue was considerably lower than that of the other tocopherols.

Analysis of the oxidation products of $\alpha$-tocopherol in lecithin liposomes revealed that $\alpha$-TQ was the main product (Fig. 2). In plant lipid liposomes, $\alpha$-tocopherol degradation and $\alpha$-TQ formation was considerably slower than in lecithin liposomes (Fig. 2). In the case of plant lipid liposomes, the amount of the formed $\alpha$-TQ corresponds only to $25 \%$ of the initial amount of $\alpha$-tocopherol after $90 \mathrm{~min}$ of the reaction. This indicates that $\alpha$-TQ is not the only one product of the reaction; however, in the present study we were not able to identify any other reaction products.

In lecithin liposomes, the main oxidation product of $\alpha$-tocopherol was $\alpha$-TQ. In the case of other tocopherol homologues, the corresponding tocopherolquinones were also formed but at considerably lower amounts (Fig. 3), even though all the tocopherols were consumed at similar rates. This indicates that $\beta$-, $\gamma$ - and $\delta$-tocopherols were oxidized mainly to products other than the corresponding TQs. Among other substrates investigated, $\alpha$-tocopherolquinol 

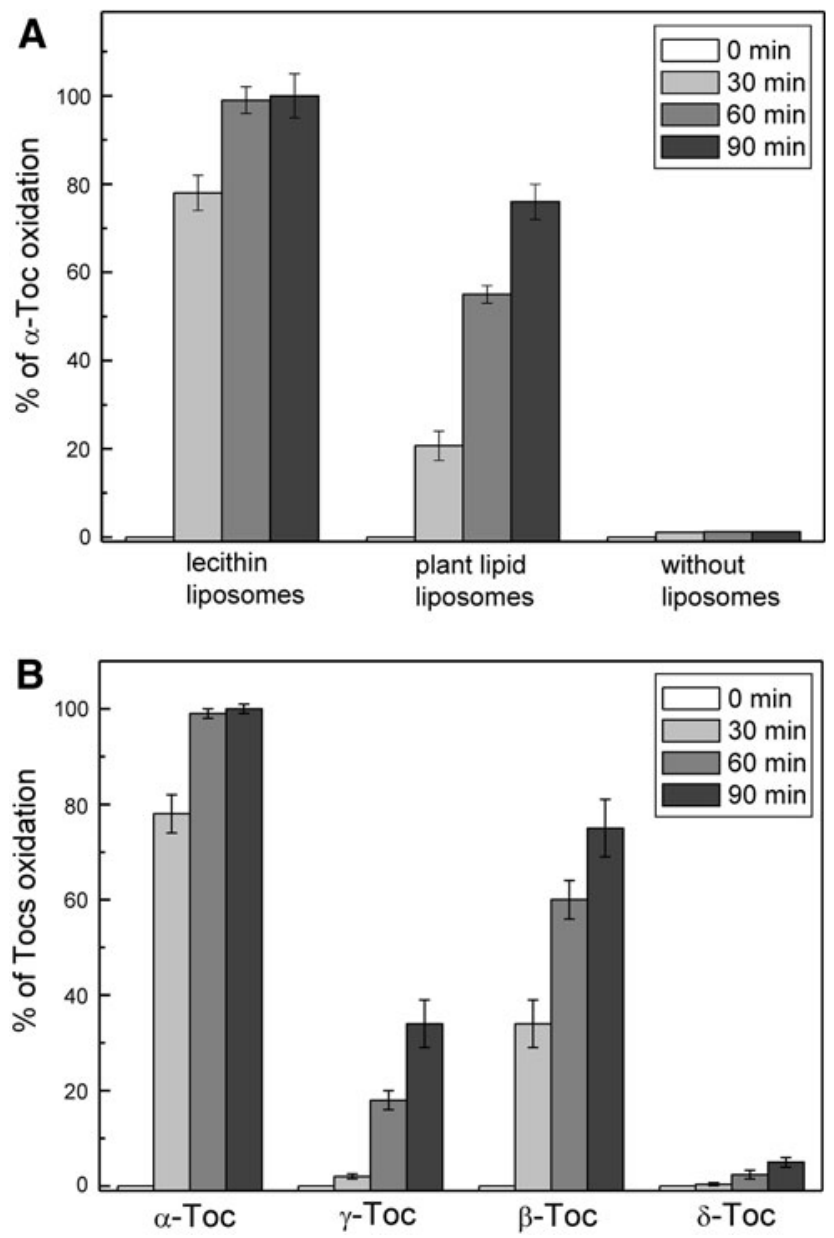

Fig. 1 a $\alpha$-Tocopherol oxidation by homogenates of etiolated shoots of Phaseolus coccineus in lecithin liposomes, plant lipid liposomes or without liposomes. b Oxidation of various tocopherols in lecithin liposomes. Other details are given in "Materials and methods". The percentage of tocopherols oxidation was calculated as [TQ]/ $([\mathrm{TQ}]+[\mathrm{Toc}]) \times 100 \%(n=3-5 \pm \mathrm{SE})$

$\left(\alpha-\mathrm{TQH}_{2}\right)$ turned out to be efficiently oxidized (total oxidation to $\alpha$-TQ after $60 \mathrm{~min}$ of the reaction). The presence of $\alpha-\mathrm{TQ}$, the reaction product, did not inhibit the reaction of $\alpha$-tocopherol oxidation (data not shown).

When the homogenates were prepared separately from hypocotyls, leaves and roots of etiolated seedlings of $P$. coccineus, the oxidase activity was the highest in extracts of leaves (Fig. 4), while extracts of roots showed no activity. Interestingly, when the activity of different parts of hypocotyls was investigated, the upper part showed the highest activity while the lowest part was nearly inactive (Fig. 4).

During the current study, purification of the enzyme from the homogenate turned out to be difficult because of the oxidase instability. After $60 \mathrm{~min}$ of the reaction in lecithin liposomes, $\alpha$-tocopherol was nearly completely oxidized by the fresh homogenate. Precipitation of the

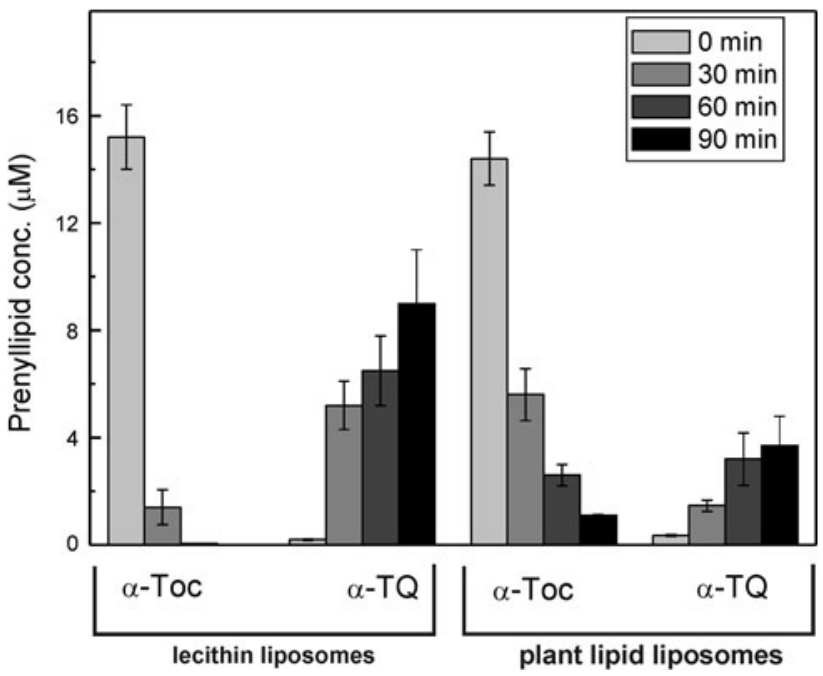

Fig. $2 \alpha$-Tocopherol oxidation by homogenates of etiolated shoots of Phaseolus coccineus in lecithin liposomes and plant lipid liposomes $(n=3-5 \pm \mathrm{SE})$

homogenate by $60 \%$ saturation of $\mathrm{NH}_{4}\left(\mathrm{SO}_{4}\right)_{2}$ caused loss of the activity by $30 \%$ (Fig. 5a). On the other hand, freezing of the homogenate at $-20{ }^{\circ} \mathrm{C}$ for $12 \mathrm{~h}$ caused decrease of the activity by as much as $70 \%$ while the precipitation of the frozen homogenate, by next $10 \%$ (Fig. 5a). When the previously frozen and precipitated homogenate was dialyzed, both in the presence and absence of copper ions, decrease of the activity to values below $10 \%$ of the control, was observed. Dialysis of the fresh homogenate resulted in loss of $30 \%$ of the activity (Fig. 5b). Moreover, the addition of different compounds to the dialysis buffer, potentially affecting the enzymatic activity such as $\alpha$-tocopherol, ascorbate and glutathione, caused additional decline of the activity (Fig. 5b). Especially in the case of ascorbate, the effect was very pronounced. Ascorbate also inhibited $\alpha$-tocopherol oxidation in liposomes when it was added directly to the reaction mixture, but the activity was rescued when ascorbate was removed by dialysis (data not shown).

Storage of the homogenate at $4{ }^{\circ} \mathrm{C}$ caused gradual loss of the oxidase activity, both of the fresh and $\mathrm{NH}_{4}\left(\mathrm{SO}_{4}\right)_{2}-$ precipitated preparation (Fig. 6). Measurements of the effect of different temperatures on the oxidase activity during the reaction revealed that both low and increased temperatures $\left(4^{\circ} \mathrm{C}\right.$ and $40{ }^{\circ} \mathrm{C}$, respectively) were inhibitory (Table 1). Boiling of the homogenate for $5 \mathrm{~min}$ completely abolished the activity. When the homogenate was stored at different temperatures and the activity analyzed at $20^{\circ} \mathrm{C}$, it was higher when the storage temperature was lower (Table 1). These observations indicate that the oxidase activity has enzymatic character that is sensitive to elevated temperatures. 

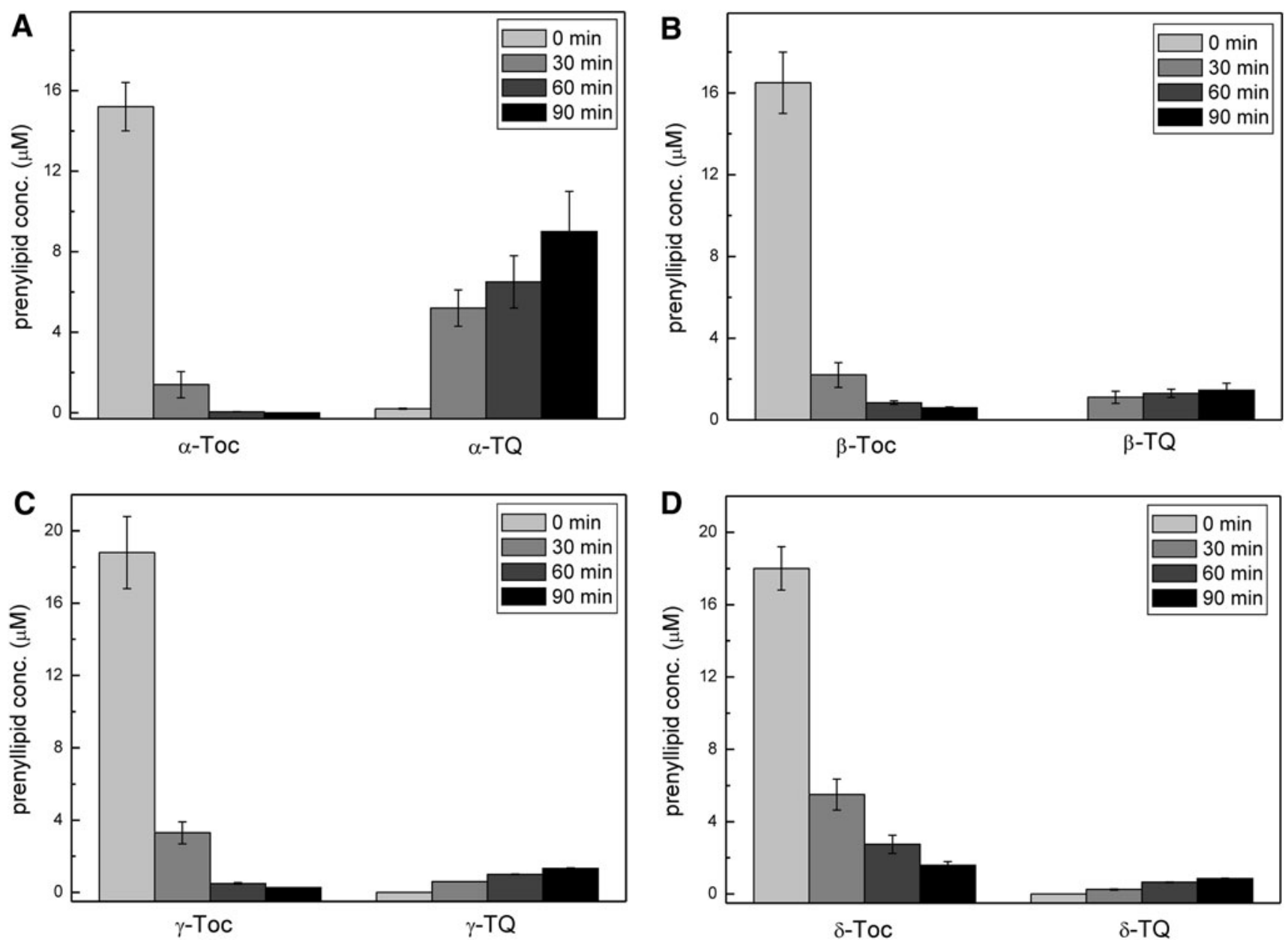

Fig. 3 Oxidation of various tocopherols by homogenates of etiolated shoots of Phaseolus coccineus in lecithin liposomes $(n=3-5 \pm$ SE)

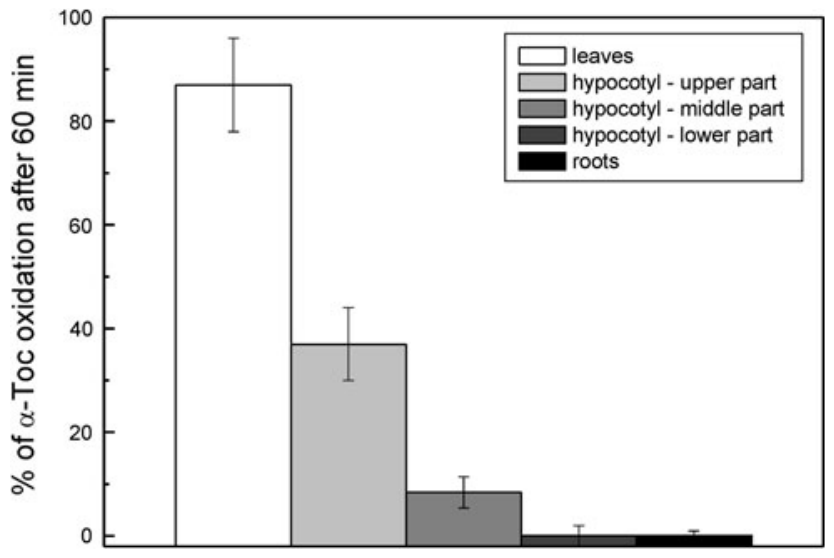

Fig. 4 Activity of homogenates of different parts of etiolated shoots of Phaseolus coccineus in the oxidation of $\alpha$-tocopherol incorporated into lecithin liposomes $(n=3-5 \pm \mathrm{SE})$

In the following experiments, we have tested several known inhibitors of oxidases (Table 2). Azide, an inhibitor of heme proteins and copper oxidases (Alcalde 2007; Mishra et al. 2012) was not inhibitory, while metabisulphite and cysteine, inhibitors of polyphenol oxidase (Guo et al. 2009) inhibited the reaction by ca. 20 and $50 \%$, respectively. Surprisingly, when the citrate-phosphate buffer was replaced by MES buffer for preparation of the homogenate, the reaction was completely inhibited. It was also found that hydrogen peroxide, the substrate of peroxidises, did not affect the reaction when added to the reaction mixture and it was also not formed during the reaction (data not shown).

\section{Discussion}

In humans, $\alpha$-tocopherol metabolism resembles the pathway of $\omega$-oxidation of fatty acids where tocopheryl hydroxychromane is formed (Zingg and Azzi 2004). In spite of the intensive research, a similar pathway was not found in plants (Kobayashi and DellaPenna 2008).

In early the 1960s, an enzymatic activity catalyzing $\alpha$-tocopherol degradation in the presence of molecular oxygen was shown in extracts of some plant species. It was also found that the presence of phospholipids was required 

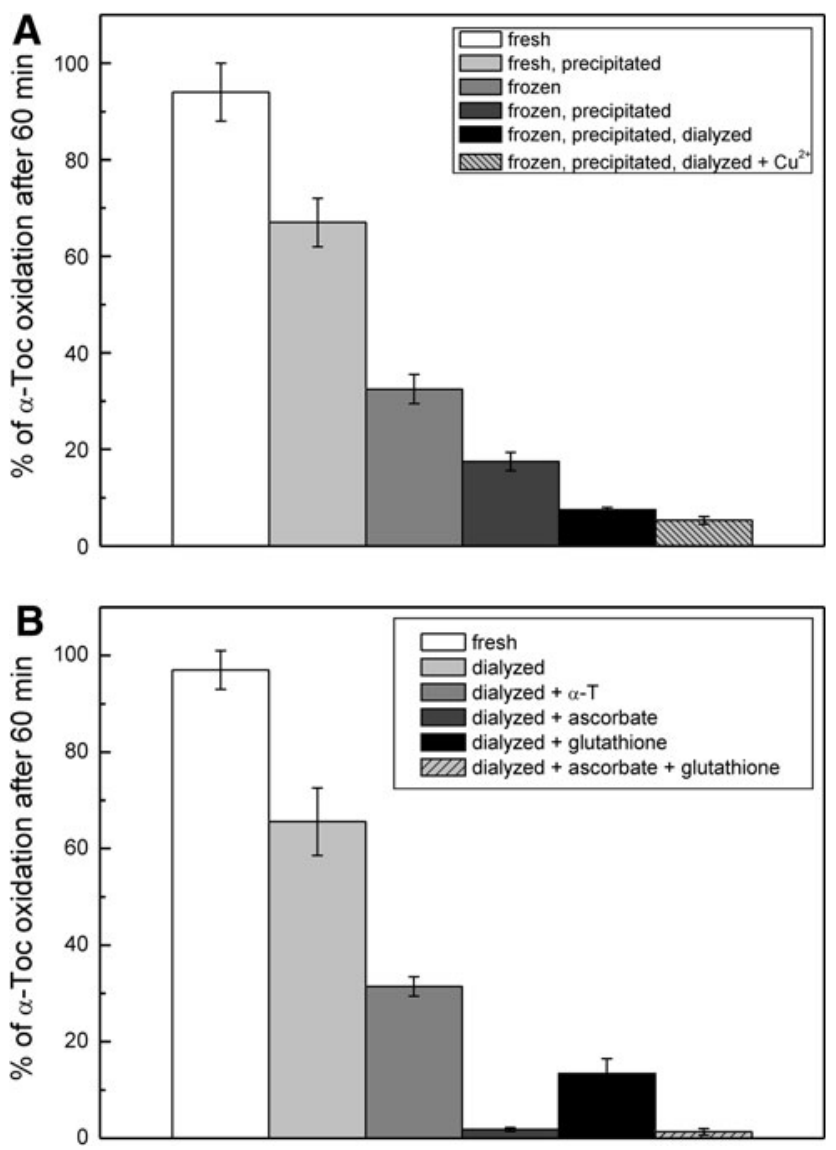

Fig. 5 Activity of homogenates of etiolated shoots of Phaseolus coccineus in the oxidation of $\alpha$-tocopherol incorporated into lecithin liposomes after different treatment of homogenates: a $\mathrm{NH}_{4}\left(\mathrm{SO}_{4}\right)_{2}$ precipitation (60\% saturation), addition of $50 \mu \mathrm{M}$ copper ions; b freezing, dialysis, addition of $10 \mathrm{mM}$ ascorbate, $10 \mathrm{mM}$ reduced glutathione or $100 \mu \mathrm{M} \alpha$-tocopherol $(n=3-5 \pm \mathrm{SE})$

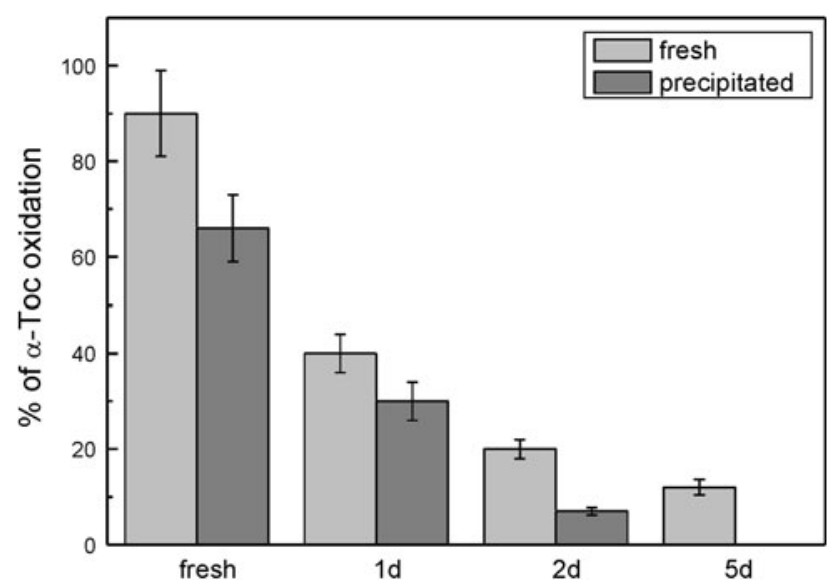

Fig. 6 The effect of storage time on the activity of fresh and $\mathrm{NH}_{4}\left(\mathrm{SO}_{4}\right)_{2}$ precipitated (60\% saturation) homogenates of etiolated shoots of Phaseolus coccineus in the oxidation of $\alpha$-tocopherol incorporated into lecithin liposomes, $d$ stands for days $(n=3-5 \pm \mathrm{SE})$
Table 1 The effect of different temperatures on the activity of frozen homogenates of etiolated shoots of Phaseolus coccineus in $\alpha$ tocopherol oxidation in the presence of lecithin liposomes $(n=3-5 \pm \mathrm{SE})$

\begin{tabular}{lc}
\hline Sample & $\begin{array}{l}\% \text { of } \alpha \text {-Toc } \\
\text { oxidation after } \\
60 \text { min }\end{array}$ \\
\hline $20{ }^{\circ} \mathrm{C}$ & $52 \pm 5$ \\
$4{ }^{\circ} \mathrm{C}$ & $5.5 \pm 3.2$ \\
$40{ }^{\circ} \mathrm{C}$ & $10.6 \pm 3.0$ \\
Boiled for $5 \mathrm{~min}$ & $0.0 \pm 0.1$ \\
Stored for $12 \mathrm{~h}$ at $36{ }^{\circ} \mathrm{C}$, measured at $20{ }^{\circ} \mathrm{C}$ & $2.0 \pm 1.5$ \\
Stored for $12 \mathrm{~h}$ at $20^{\circ} \mathrm{C}$, measured at $20^{\circ} \mathrm{C}$ & $6.1 \pm 2.1$ \\
Stored for $12 \mathrm{~h}$ at $4{ }^{\circ} \mathrm{C}$, measured at $20{ }^{\circ} \mathrm{C}$ & $20.1 \pm 2.2$ \\
Stored for $12 \mathrm{~h}$ at $-20{ }^{\circ} \mathrm{C}$, measured at $20{ }^{\circ} \mathrm{C}$ & $26.2 \pm 2.3$
\end{tabular}

Table 2 The effect of different inhibitors on the activity of fresh homogenates of etiolated shoots of Phaseolus coccineus in $\alpha$ tocopherol oxidation in the presence of lecithin liposomes measured at $20 \pm 2{ }^{\circ} \mathrm{C}(n=3-5 \pm \mathrm{SE})$

\begin{tabular}{ll}
\hline Sample & $\%$ of $\alpha$-Toc oxidation after $60 \mathrm{~min}$ \\
\hline Control & $84 \pm 9$ \\
$1 \mathrm{mM}$ azide & $88 \pm 5$ \\
$1 \mathrm{mM}$ sodium metabisulphite & $70 \pm 5$ \\
$1 \mathrm{mM}$ cysteine & $42 \pm 4$ \\
$50 \mathrm{mM}$ MES buffer, pH 5.5 & $0 \pm 1$ \\
\hline
\end{tabular}

${ }^{a}$ The buffer was used for homogenate preparation and during the reaction instead of the citrate-phosphate buffer

for the oxidase activity (Barlow and Gaunt 1968). The cellfree homogenates of seeds and etiolated tissues were most active in this respect; nevertheless, green leaves were also active to some extent (Hardy et al. 1991).

In the present study, earlier reports have been confirmed where the presence of phospholipids was shown to be required for the reaction. Moreover, we have shown that the enzyme is active also in liposomes prepared from plant membrane lipids, i.e., mainly neutral glycolipids. This indicates that lipid environment, where the tocopherols reside, is required for oxidase activity but not necessarily the presence of phosphatidylcholine. The positively charged choline moiety of lecithin probably only facilitates enzyme binding to the membrane. The solubility of the oxidase in lipid-free homogenate indicates that the enzyme is easily removed from natural membranes and is a peripheral membrane protein.

It was originally presumed that lipoxygenase might be responsible for the oxidase activity. However, this was excluded by experiments involving added linolenate that should stimulate lipoxygenase activity, but the effect was 
just the opposite (Gaunt and Stowe 1967). As it was previously shown (Murillo et al. 1978), the oxidase is not totally specific against $\alpha$-tocopherol, but also other tocopherols can be oxidized although at a lower rate. The relative activities for $\alpha$-, $\beta$-, $\gamma$ - and $\delta$-tocopherols were found to be as 100:50:50:25, respectively (Murillo et al. 1978). In the present study, the obtained activities were evidently different: $\alpha \gg \beta>\gamma>\delta$. Moreover, Hardy et al. (1991) showed the higher activity of the fresh $P$. sativum extract against $\gamma$-tocopherol than against $\alpha$ and $\delta$ homologues. These differences might result from plant species-specific differences of the oxidase specificity and/or different experimental conditions used in those studies.

We have found that in the case of $\alpha$-tocopherol, $\alpha$-TQ was the main oxidation product, while during oxidation of other tocopherols, the corresponding TQs were also formed but at lower amounts. This indicates that mainly other oxidation products are formed in the case of $\beta-, \gamma$ - and $\delta$-tocopherols; however, we were not able to identify them presently.

As demonstrated presently, due to the high instability of the oxidase upon different treatments, further purification of the enzyme turned out to be impossible. In contrast to our study, Gaunt et al. (1980) found that the enzyme in the membrane-free homogenate $(100,000 \mathrm{~g}$ supernatant $)$ obtained from $P$. sativum is stable to ammonium sulphate precipitation and to storage at $0{ }^{\circ} \mathrm{C}$ for $7-10$ days. However, their crude cell-free extract was rapidly losing the activity on storage.

The obtained results shed some light on the nature of the oxidase. It should be noted that in contrast to some studies (Hardy et al. 1991), we have shown that the oxidase requires oxygen for the reaction (data not shown). Ascorbate was shown to cause irreversibly inhibition of polyphenol oxidase (Guo et al. 2009). In our case, the inhibition is reversible because removal of ascorbate by dialysis recovered the activity. Therefore, it is possible that ascorbate reduces one-electron oxidized tocopherol (tocopheroxyl radical) back to tocopherol and its oxidation is not observed. This indicates that ascorbate is not a direct inhibitor of the enzyme. Our results also showed that hydrogen peroxide is not required as the substrate of the reaction, eliminating peroxidases as potential candidates. Moreover, the finding that hydrogen peroxide is not formed as the product of the oxidase reaction eliminates also flavin oxidases. The inhibitory effect of cysteine and metabisulphite points to polyphenol oxidase (Guo et al. 2009). On the other hand, azide, an inhibitor of multi-copper oxidases such as polyphenol oxidases and laccases (Alcalde 2007; Mishra et al. 2012), turned out to be not active in our study. The tocopherol oxidase was also shown to be not significantly inhibited by cyanide (Hardy et al. 1991), the inhibitor of some heme proteins and multi-copper oxidases (Alcalde
2007). We have also found that catechol, the well-known substrate of polyphenol oxidases and laccases (Alcalde 2007; Guo et al. 2009) is not oxidized by the Phaseolus homogenates (data not shown), indicating a high substrate specificity of the tocopherol oxidase.

The observation of the highest activity of tocopherol oxidase in the leaves and its decreasing activity towards the roots (Fig. 4), correlates well with the $\gamma$-tocopherol content in $P$. coccineus seedlings observed previously (Szymańska and Kruk 2008). The decline of $\gamma$-tocopherol during seedlings development was mainly due to $\gamma$-tocopherol degradation and not as a result of $\gamma$ - to $\alpha$-tocopherol conversion (Szymańska and Kruk 2008). The presence of the oxidase in young leaves prevents also accumulation of higher amounts of $\alpha$-tocopherol in these leaves. The physiological function of this process cannot be fully understood yet, but there are indications on specific functions of $\gamma$-tocopherol in young tissue in their preventing against osmotic stress (Szymańska and Kruk 2008). The observed $\gamma$-tocopherol degradation might be caused by tocopherol oxidase activity in young runner bean leaves. For some, still unidentified reasons, $\gamma$-tocopherol must be quickly removed in maturing tissues. Moreover, Kobayashi and DellaPenna (2008) showed that $\alpha$-tocopherol can be reversibly oxidized to $\alpha-\mathrm{TQH}_{2}$ in Arabidopsis. This indicates the possibility that in the recycling reaction of $\alpha$-tocopherol in chloroplasts, tocopherol oxidase is engaged. The above-discussed issues clearly need further research.

Author contribution R.S. performed the experiments, wrote the text and prepared figures. J.K. designed the experiments, wrote the text and prepared figures.

Acknowledgments This project was supported by grant 2011/01/B/ NZ1/00079 obtained from the National Center of Science.

Open Access This article is distributed under the terms of the Creative Commons Attribution License which permits any use, distribution, and reproduction in any medium, provided the original author(s) and the source are credited.

\section{References}

Alcalde M (2007) Laccases: biological functions, molecular structure and industrial applications. In: MacCabe AP, Polaina J (eds) Industrial enzymes. Springer, Berlin, pp 461-476

Barlow SM, Gaunt JK (1968) Studies on the degradation of $\alpha$-tocopherol by plant extracts. Proc Biochem Soc 109:8P

Gaunt JK, Barlow SM (1971) The breakdown of $\alpha$-tocopherol by plant homogenates. In: McCornic DB, Wright LD (eds) Vitamins and Coenzymes. Part C. Methods in Enzymology, vol 18. Academic Press, New York, pp 396-403

Gaunt JK, Plumpton ES (1978) Control in vitro of tocopherol oxidase by light in extracts from leaves of Xathium strumarium L. Biochem Soc Trans 6:143-145 
Gaunt JK, Plumpton ES (1980) Photoperiodic control in vivo and in vitro of tocopherol oxidase in Xathium strumarium $\mathrm{L}$. Biochem Soc Trans 8:187-188

Gaunt JK, Stowe BB (1967) Uptake and metabolism of vitamin E and K by pea stem sections. Plant Physiol 42:859-862

Gaunt JK, Matthews GM, Plumpton ES (1980) Control in vitro of tocopherol oxidase by light and by auxins, kinetin, gibberellic acid, abscisic acid and ethylene. Biochem Soc Trans 8:186-188

Gruszka J, Pawlak A, Kruk J (2008) Tocochromanols, plastoquinol, and other biological prenylolipids as singlet oxygen quenchersdetermination of singlet oxygen quenching rate constants and oxidation products. Free Rad Biol Med 45:920-928

Guo L, Ma Y, Shi J, Xue S (2009) The purification and characterisation of polyphenol oxidase from green bean (Phaseolus vulgaris L.). Food Chem 117:143-151

Hakansson R, Jagerstad M (1990) The effect of thermal inactivation of lipoxygenase on the stability of vitamin $\mathrm{E}$ in wheat. J Cer Sci 12:177-186

Hardy DJ, Gallegos MAV, Gaunt JK (1991) Metabolism of tocopherol by Pisum sativum. Phytochemistry 30:1099-1105

Kobayashi N, DellaPenna D (2008) Tocopherol metabolism, oxidation and recycling under high light stress in Arabidopsis. Plant $\mathrm{J}$ 55:607-618

Kruk J (1988a) Charge-transfer complexes of plastoquinone and $\alpha$-tocopherol quinone in vitro. Biochim Biophys Acta 30:143-149
Kruk J (1988b) Physicochemical properties of charge-transfer complexes of plastoquinone and $\alpha$-tocopherol quinone, and their possible role in vivo. Biophys Chem 32:51-56

Lushchak VI, Semchuk NM (2012) Tocopherol biosynthesis: chemistry, regulation and effects of environmental factors. Acta Physiol Plant 34:1607-1628

Mène-Saffrané L, DellaPenna D (2010) Biosynthesis, regulation and functions of tocochromanols in plants. Plant Physiol Biochem 48:301-309

Mishra BB, Gautam S, Sharma A (2012) Purification and characterisation of polyphenol oxidase (PPO) from eggplant (Solanum melongena). Food Chem 134:1855-1861

Munne-Bosch S, Alegre L (2002) The function of tocopherols and tocotrienols in plants. Crit Rev Plant Sci 21:31-57

Murillo E, Plumpton SE, Gaunt JK (1978) The properties and distribution of $\alpha$-tocopherol oxidase in plants. Biochem Soc Trans 4:486-487

Szymańska R, Kruk J (2008) $\gamma$-Tocopherol dominates in young leaves of runner bean (Phaseolus coccineus L.) under a variety of growing conditions: the possible functions of $\gamma$-tocopherol. Phytochemistry 69:21420-22148

Zingg JM, Azzi A (2004) Non-antioxidant activities of vitamin E. Curr Med Chem 11:1113-1133 